\title{
Characteristics of pollutant emission from motor vehicles for the purposes of the Central Emission Database in Poland
}

Within the Institute of Environmental Protection - National Research Institute the Central Emission Database is being established. The Database will cover the most important emission sectors from anthropogenic activities, including usage of motor vehicles. The intensity of emissions of individual pollutants is the input data to air pollution dispersion models. Based on calculations performed by the air pollution dispersion models concentration of pollutants dispersed in atmospheric air (pollution immission) is provided. The annual average immision for a selected place in Poland is a measure of the threat to environment. In order to determine the intensity of pollutant emissions from motor vehicles it is necessary to recognize the intensity of vehicle motion and the volume of emission of pollutants depending on the type of vehicle motion. The task presented in this article is to determine the characteristics of pollutant emissions from motor vehicles depending on the type of their motion. The mean value of vehicle speeds was used to characterize the type of vehicle motion. The emission of pollutants from vehicles is therefore characterized by the dependence of road emissions of pollutants on the average speed of vehicles. The characteristics were determined for cumulated categories of motor vehicles: passenger cars, light commercial vehicles as well as heavy duty trucks and buses. The results of the inventory of pollutant emissions from motor vehicles in Poland in 2016 were used to determine the characteristics of pollutant emissions.

Key words: pollutant emission characteristics, motor vehicles, central emission base

\section{Introduction}

The Institute of Environmental Protection - National Research Institute has undertaken a global-scale unique enterprise to estimate emission in spatial scale from both natural and anthropogenic sources, as well as modelling of the dispersion of pollutants. As a result of this project, it will be possible to determine the spatial distribution of immission of pollution (concentrations of pollutants dispersed in the air) in Poland, averaged over the year for which immission was determined. Information on pollutant emissions is provided as a part of the Central Emission Database program. Estimated substances are listed below:

- carbon monoxide - $\mathrm{CO}$,

- non-methane volatile organic compounds - NMVOC,

- nitrogen oxides reduced to nitrogen dioxide $-\mathrm{NO}_{\mathrm{x}}$,

- total suspended particles - TSP,

- particulate matter PM10 - PM10,

- particulate matter PM2.5 - PM2.5,

- carbon dioxide $-\mathrm{CO}_{2}$,

- sulphur oxides reduced to sulphur dioxide $-\mathrm{SO}_{2}$,

- ammonia - $\mathrm{NH}_{3}$,

- nickel - Ni,

- cadmium - Cd,

- lead $-\mathrm{Pb}$,

- benzo(a)pyrene - B(a)P,

- mercury - Hg,

- arsenic - As.

In order to model the emission of pollutants it is necessary to provide data of an extensive and intensive nature, on the functioning of the sources of pollutant emissions and data on emission characteristics. This article presents the results of elaboration of emission characteristics from road transport vehicles.

\section{Methodology for determining the characteristics of pollutant emissions from motor vehicles}

Emission of pollutants from the set of motor vehicles is a superposition of pollutant emissions. This is in line with the assumption that the emissions inventory includes substances in the state emitted from emission sources $[2,5]$ Emission of pollutants from motor vehicles is modelled as the sum of $[2,4,5,10,11]$ :

- emission from engine heated to a stable temperature,

- emission during the heating of the engine,

- emission from fuel evaporation from the fuel system of the vehicle,

- particular matter emission related to tribological processes.

The annual emission of pollutants (pollutant emission averaged over 1 year) $-E_{a}$ from the set of motor vehicles is equal:

$$
\mathrm{E}_{\mathrm{a}}=\sum_{\mathrm{i}=1}^{\mathrm{N}} \mathrm{p}_{\mathrm{i}} \cdot \mathrm{b}_{\mathrm{i}}
$$

where: $\mathrm{p}$ - annual mileage of the vehicle, $\mathrm{b}$ - emission of pollutant, $\mathrm{N}$ - number of vehicles in the set.

According to the Central Emission Database establishing assumptions establishing, there are analyses conducted for the following cumulative categories of motor vehicles:

- passenger cars,

- light commercial vehicles (light duty vehicles),

- heavy duty trucks,

- buses,

- motorcycles and mopeds.

To estimate the emission of pollutants from cumulated categories of motor vehicles, the results of the inventory of pollutants from motor vehicles in Poland in 2017 calculated by COPERT 5 software were used [9]. 
Input data to COPERT model are $[1-3,9,10]$ :

- number of vehicles,

- distance travelled (annual mileage),

- mileage share in the urban areas, rural areas and highways,

- travelling velocity for urban areas, rural areas and highways,

- monthly temperature ( $\min$ and max),

- the sulphur content in fuels,

- the lead content in fuels,

- fuel compounds,

- heavy metals content in fuels,

- vapour pressure of fuels,

- average trip length.

The methodology of the selection of the COPERT input data has been described in publications [1-3].

With the reference to equation (1), the emission of pollutants from road transport is assumed as the value characterizing the pollutant emission from motor vehicles. The emission of pollutants depends in an operational calculus on the vehicle speed, determining the engine operating states: rotational speed and torque - engine load measures [5]. In pollutants emission modelling, the most frequently used zero-dimensional characteristic is the average vehicle`s speed $-\mathrm{v}_{\mathrm{AV}}$. In this article, dependence of emission of pollutants on the average speed of the vehicle is assumed as a characteristic of the emission of pollutants.

The average value of the road emission of the pollutant " $\mathrm{j}$ " for the set of vehicles is equal:

$$
b_{j}=\frac{\sum_{i=1}^{N} p_{i} \cdot b_{i j}}{\sum_{i=1}^{N} p_{i}}
$$

In fact, it is not possible to average the results for individual vehicles, therefore, the results for the elementary categories of motor vehicles in the cumulative categories are averaged:

$$
b_{j}=\frac{\sum_{k=1}^{K} N_{k} \cdot p_{k} \cdot b_{k j}}{\sum_{k=1}^{K} p_{k} \cdot b_{k j}}
$$

where: $\mathrm{K}$ - number of elementary categories in the cumulative category, $\mathrm{N}_{\mathrm{k}}$ - number of vehicles in the category ,k',.

This paper presents the emission characteristics of motor vehicles for the following pollutants, particularly harmful to the health of living organisms due to the properties of the substances and volume of the emission road: carbon monoxide, non-methane volatile organic compounds, oxides of nitrogen and particulate matter divided into dimensional fractions: total suspended particles, PM10 and PM2.5 particulate matter.

\section{Emission characteristics of selected pollutants from motor vehicles in Poland for 2017}

According to the equation (3) the average emission of each pollutant was determined (on the basis of the calculated values of the national annual emission for the assumed values of average vehicle speeds for cumulated categories of motor vehicles). The sets of average emissions of pollutants for cumulated vehicle categories in the domain of average vehicle speed have been approximated by a polynomial function from the $3^{\text {rd }}$ to the $6_{\text {th }}$ degree. By that means, the analytical form of the characteristics of road emissions of pollutants was determined for individual categories of motor vehicles. Figures 1-30 present the emission characteristics of selected pollutants from motor vehicles in Poland for 2017. Figures 1-6 present the pollutants emission characteristics from passenger cars.

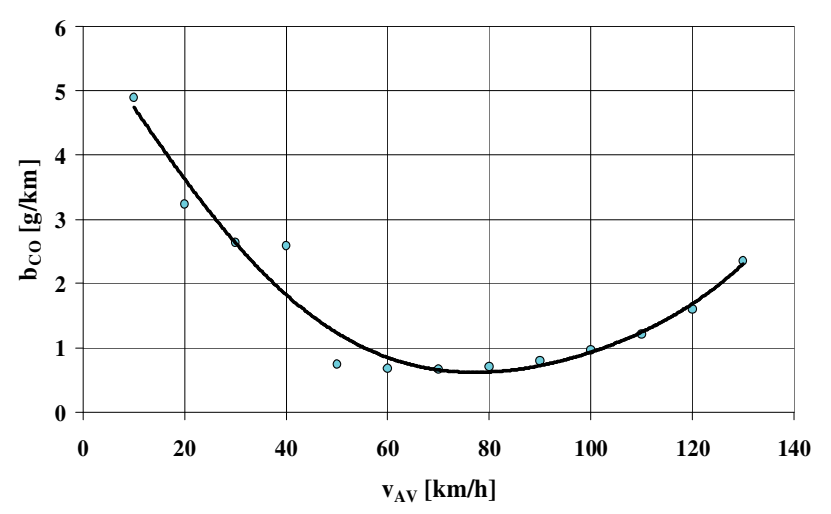

Fig. 1. The characteristic of the specific distance emission of carbon oxide $-b_{\mathrm{CO}}$ from passenger cars

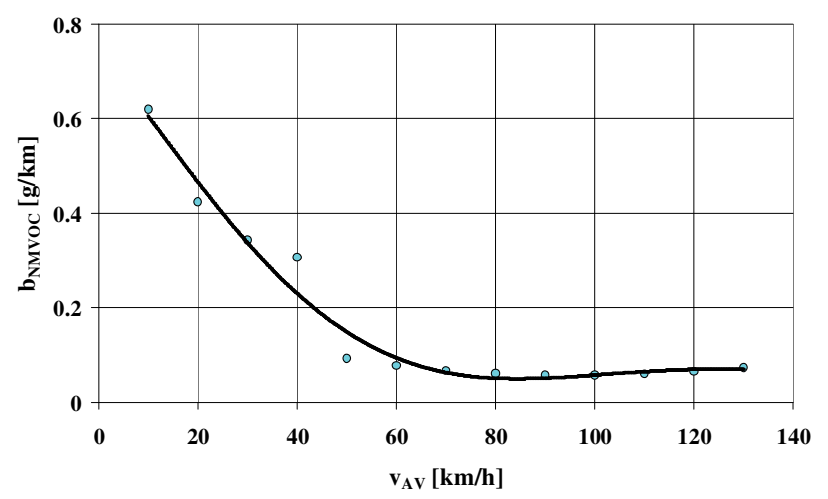

Fig. 2. The characteristic of the specific distance emission of non-methane volatile organic compounds - $b_{\mathrm{NMVOC}}$ from passenger cars

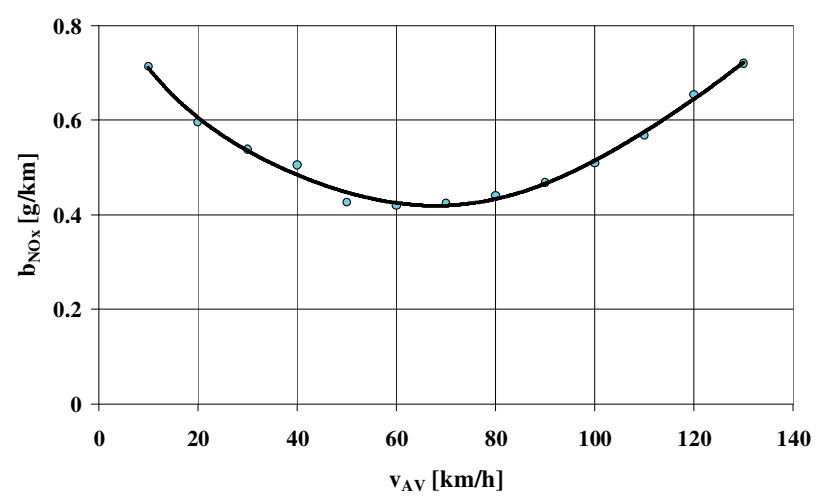

Fig. 3. The characteristic of the specific distance emission of nitrogen oxides $-b_{\mathrm{NOx}}$ from passenger cars 


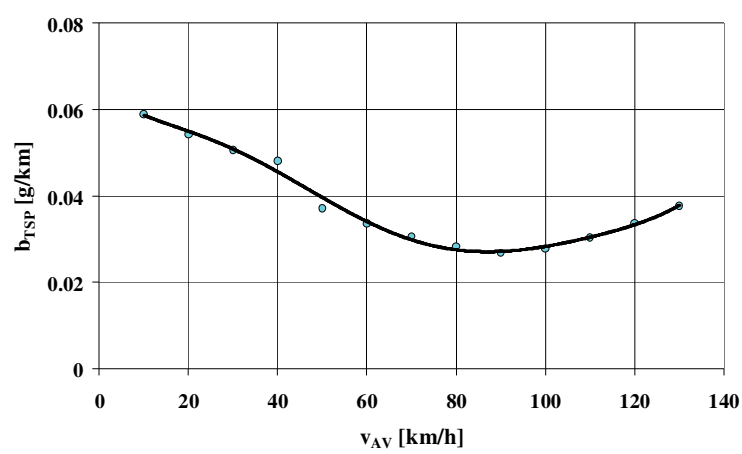

Fig. 4. The characteristic of the specific distance emission of total particulate matter $-b_{\text {TPM }}$ from passenger cars

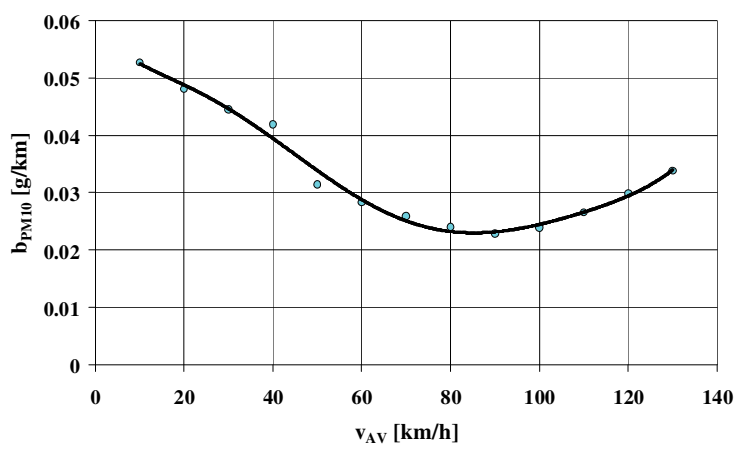

Fig. 5. The characteristic of the specific distance emission of particulate matter PM10 - $\mathrm{b}_{\mathrm{PM} 10}$ from passenger cars

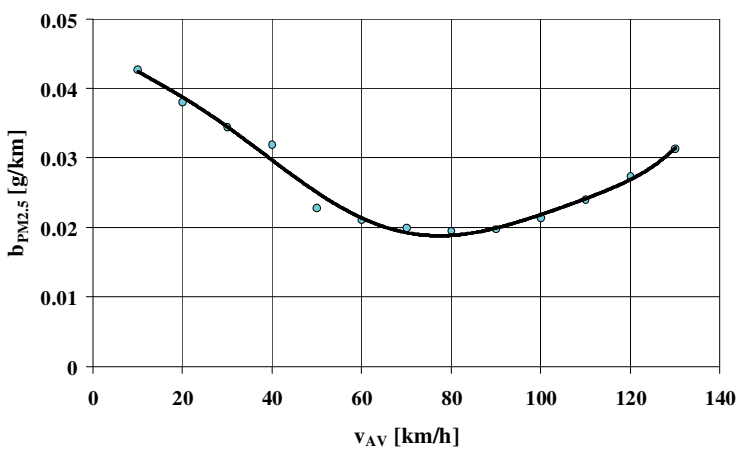

Fig. 6. The characteristic of the specific distance emission of particulate matter PM10 - $\mathrm{b}_{\mathrm{PM} 2.5}$ from passenger cars

For passenger cars, there is a significant sensitivity of emission of pollutants to travel velocity. For low average speed - in conditions of strong dynamic properties of the speed process - in most cases, road emissions are significantly higher than for moderate average speed. The sensitivity of pollutant emissions to the dynamic work states is particularly high for spark-ignition engines $[4-6,11]$ and the share of these engines in the cumulative category of passenger cars is high [1-3]. There is also a tendency of increasing the emission of road pollutants for a very high average speed, which results in a high engine load. For particulate emissions from sources other than the exhaust system, emission increasing is mainly due to the frictional power at the contact of the wheels with the road surface.

Figures 7-12 present the pollutants emission characteristics from light commercial vehicles.

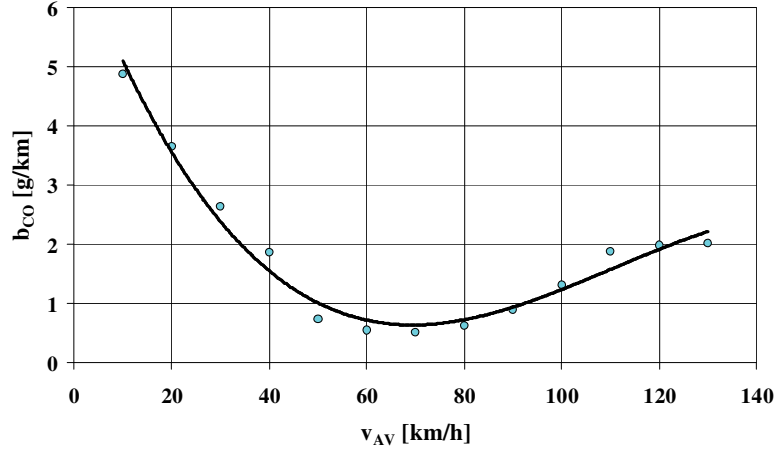

Fig. 7. The characteristic of the specific distance emission of carbon oxide $-\mathrm{b}_{\mathrm{CO}}$ from light commercial vehicles

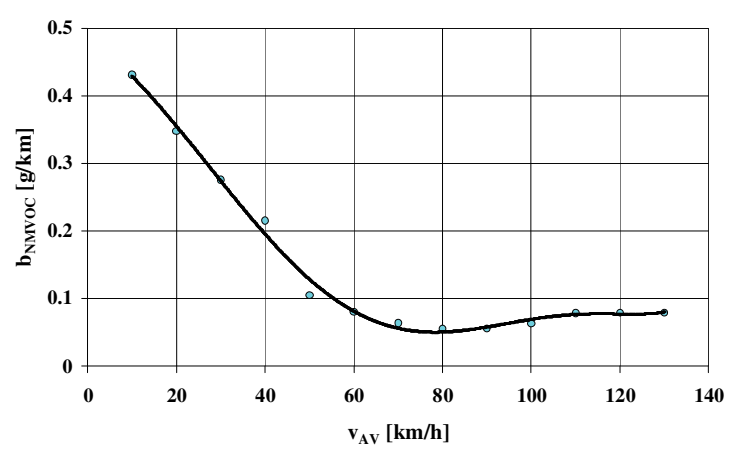

Fig. 8. The characteristic of the specific distance emission of non-methane volatile organic compounds $-\mathrm{b}_{\mathrm{NMVOC}}$ from light commercial vehicles

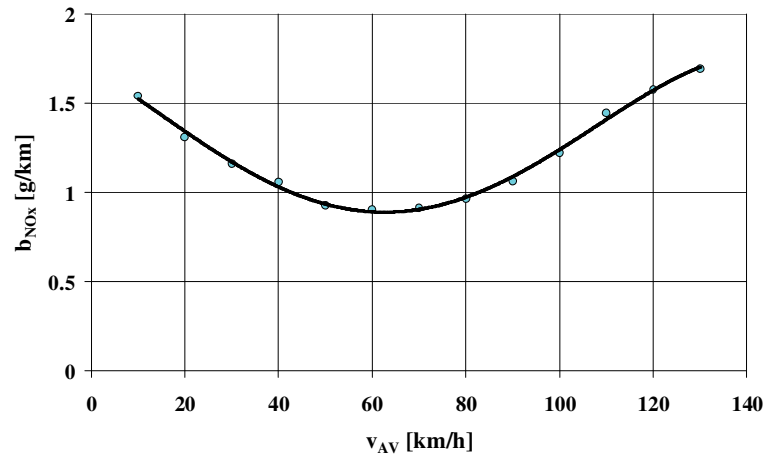

Fig. 9. The characteristic of the specific distance emission of nitrogen oxides $-b_{\mathrm{NOx}}$ from light commercial vehicles

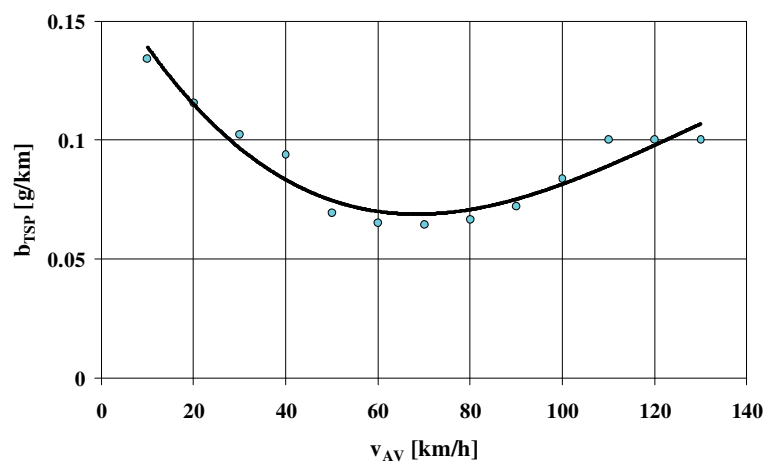

Fig. 10. The characteristic of the specific distance emission of total particulate matter $-b_{\text {TPM }}$ from light commercial vehicles 


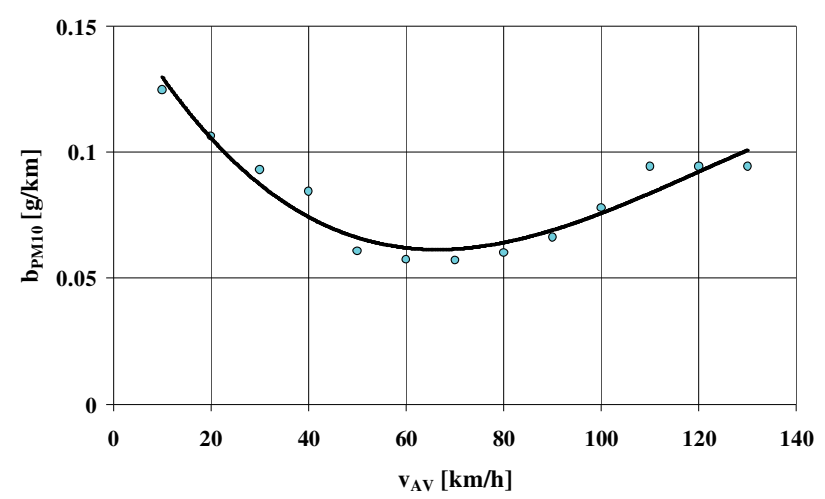

Fig. 11. The characteristic of the specific distance emission of particulate matter PM10 - b $\mathrm{P}_{\mathrm{PM} 10}$ from light commercial vehicles

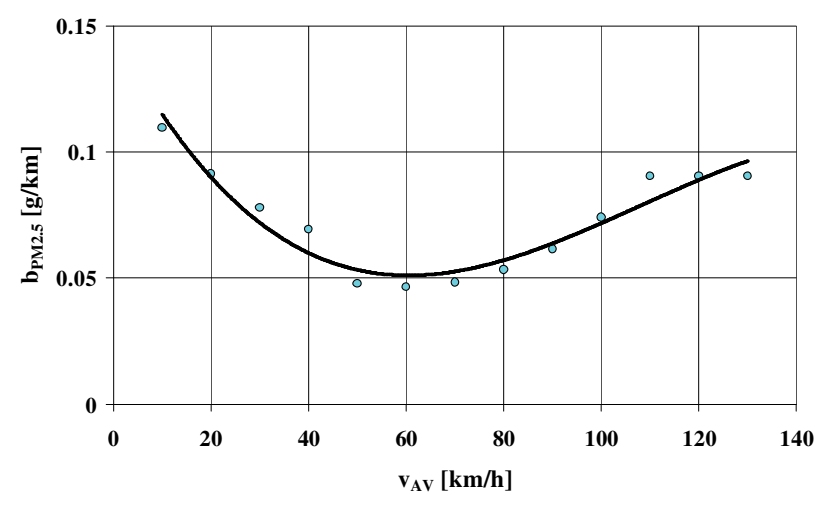

Fig. 12. The characteristic of the specific distance emission of particulate matter PM2.5 - $\mathrm{b}_{\mathrm{PM} 2.5}$ from light commercial vehicles

The pollutant emission characteristics of light commercial vehicles indicate a significant similarity to the characteristics of passenger cars. In the case of substances emission of which strongly depends on the engine and the vehicle load (primarily nitrogen oxides and particulate matter), road emission from light commercial vehicles is higher than for passenger cars.

Figures 13-18 present the pollutants emission characteristics from heavy duty trucks.

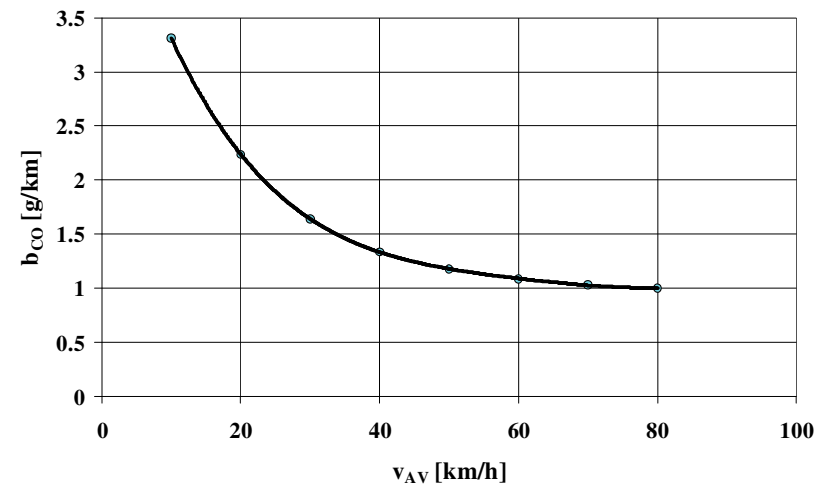

Fig. 13. The characteristic of the specific distance emission of carbon oxide $-b_{\mathrm{CO}}$ from heavy duty trucks

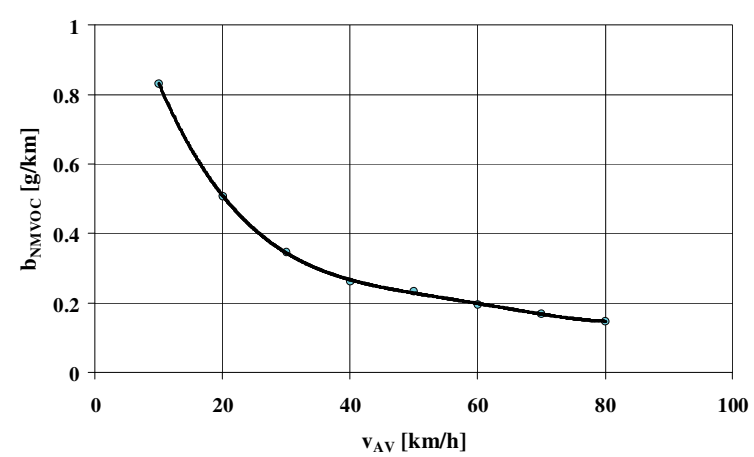

Fig. 14. The characteristic of the specific distance emission of nonmethane volatile organic compounds $-b_{\mathrm{NMVOC}}$ from heavy duty trucks

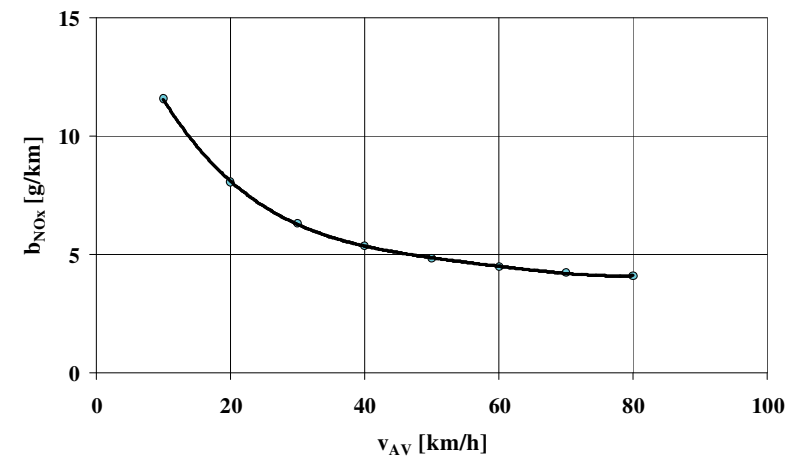

Fig. 15. The characteristic of the specific distance emission of nitrogen oxides $-b_{\mathrm{NOx}}$ from heavy duty trucks

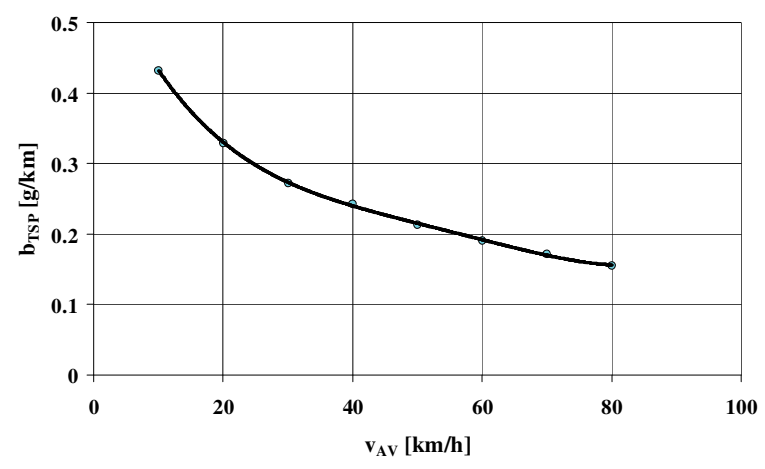

Fig. 16. The characteristic of the specific distance emission of total particulate matter $-b_{\text {TPM }}$ from heavy duty trucks

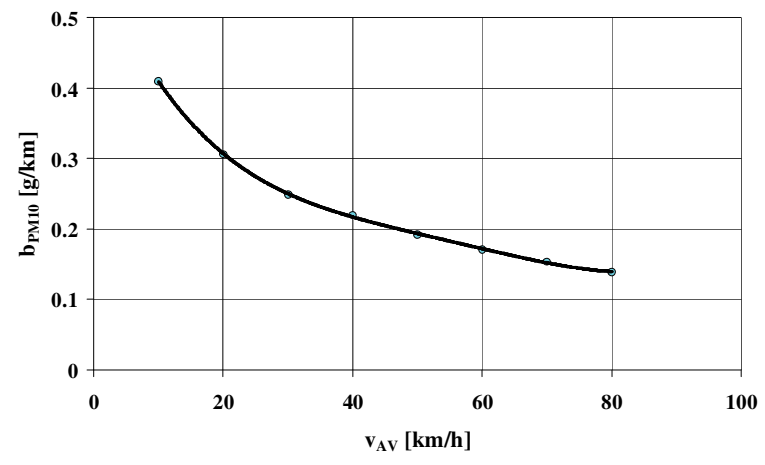

Fig. 17. The characteristic of the specific distance emission of particulate matter PM10 - b PM10 $_{\text {Prom heavy duty trucks }}$ 


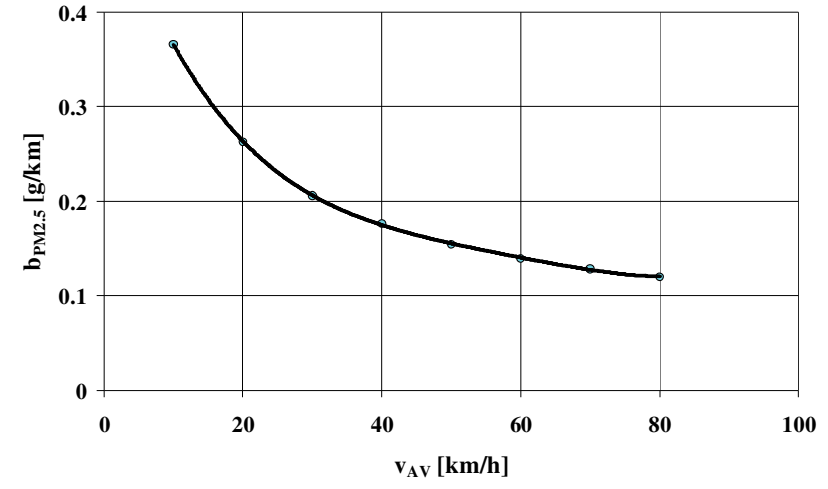

Fig. 18. The characteristic of the specific distance emission of particulate matter PM2.5 - $\mathrm{b}_{\mathrm{PM} 2.5}$ from heavy duty trucks

The dependence of road pollutants emissions on the average speed of vehicles for heavy duty trucks is different than for passenger cars and light commercial vehicles. A tendency of emission decreasing is observed for increasing vehicle speed. This is mainly due to the fact that there are no vehicles with spark ignition engines in the cumulated category of heavy duty trucks. Obviously, road emissions from heavy duty trucks are higher than emissions from light vehicles.

Figures 19-24 present the pollutants emission characterristics from buses.

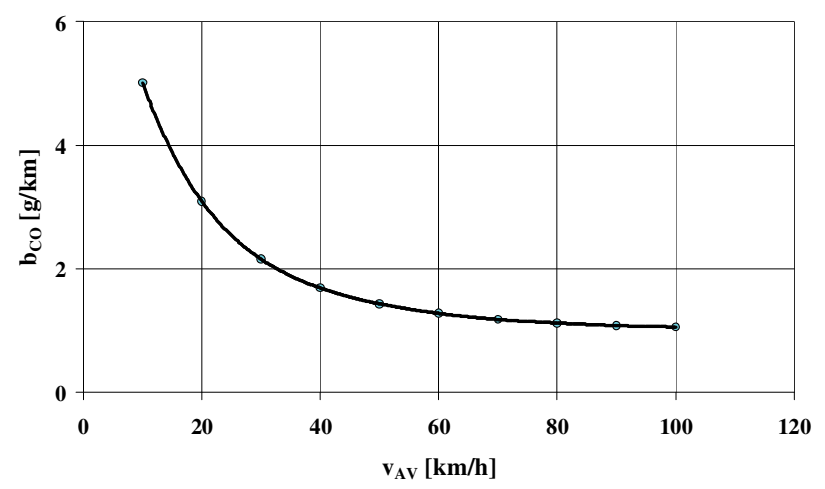

Fig. 19. The characteristic of the specific distance emission of carbon oxide $-b_{\mathrm{CO}}$ from buses

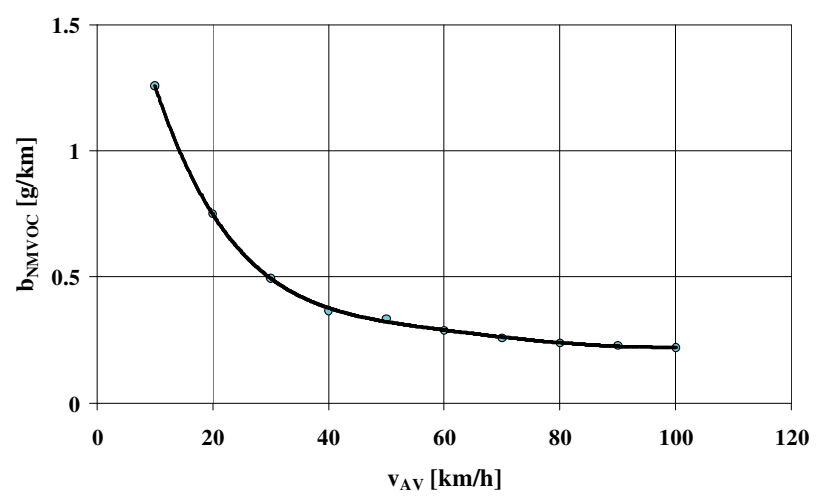

Fig. 20. The characteristic of the specific distance emission of nonmethane volatile organic compounds $-b_{\mathrm{NMVOC}}$ from buses

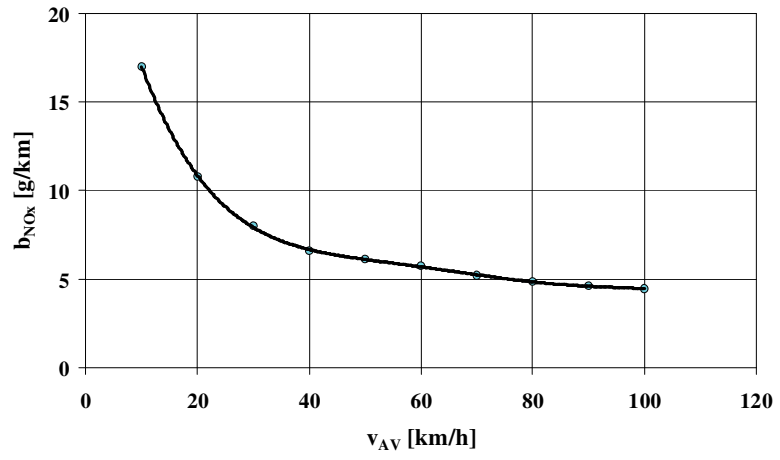

Fig. 21. The characteristic of the specific distance emission of nitrogen oxides $-b_{\mathrm{NOx}}$ from buses

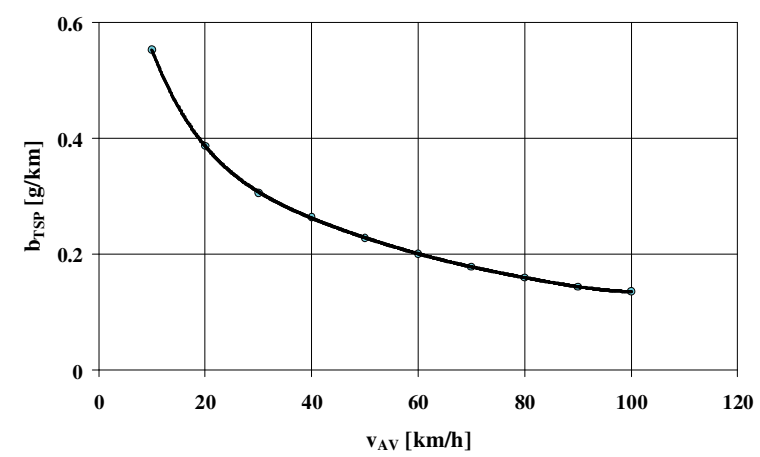

Fig. 22. The characteristic of the specific distance emission of total particulate matter $-b_{\text {TPM }}$ from buses

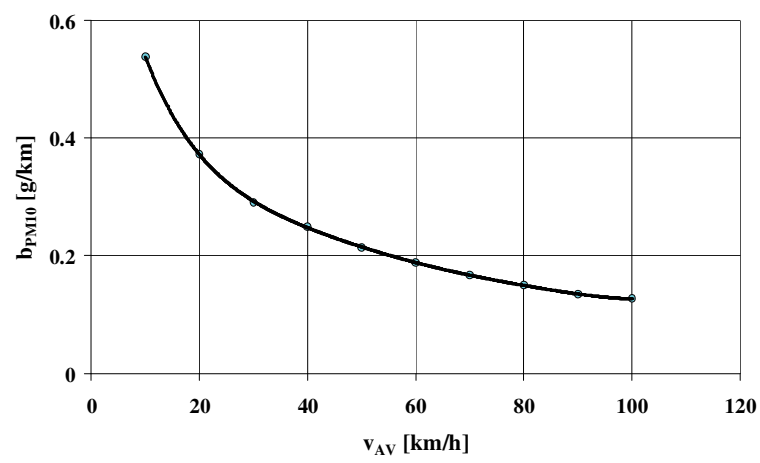

Fig. 23. The characteristic of the specific distance emission of particulate matter PM10 - b PM10 $_{\text {from buses }}$

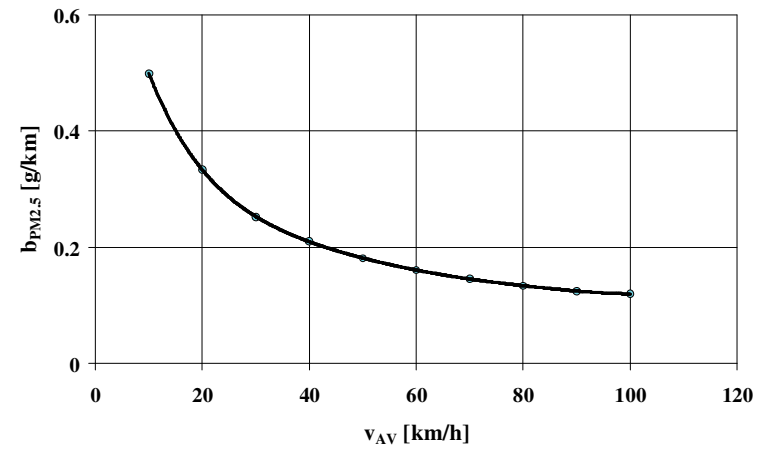

Fig. 24. The characteristic of the specific distance emission of particulate matter PM2.5- bM10 $_{\mathrm{PM}}$ from buses 
The emission characteristics for buses are similar to those for heavy duty trucks. Therefore, the cumulative categories of heavy duty trucks and buses are often combined in the modeling of pollutant emissions from motor vehicles.

Figures 25-30 present the pollutants emission characteristics from motorcycles and mopeds.

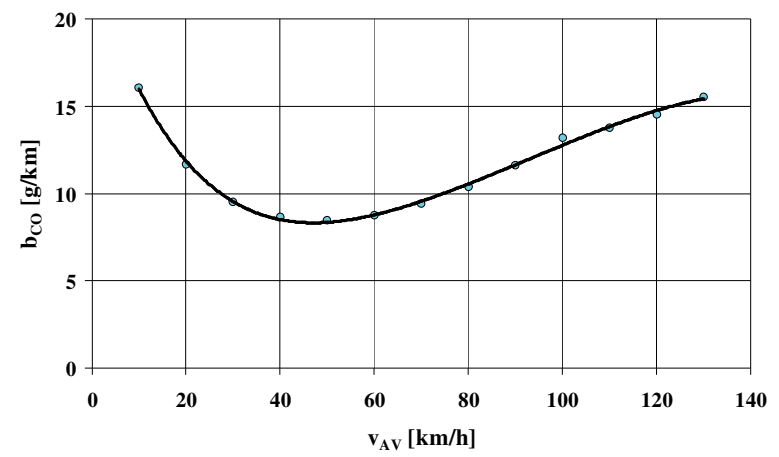

Fig. 25. The characteristic of the specific distance emission of carbon oxide $-b_{\mathrm{CO}}$ from motorcycles and mopeds

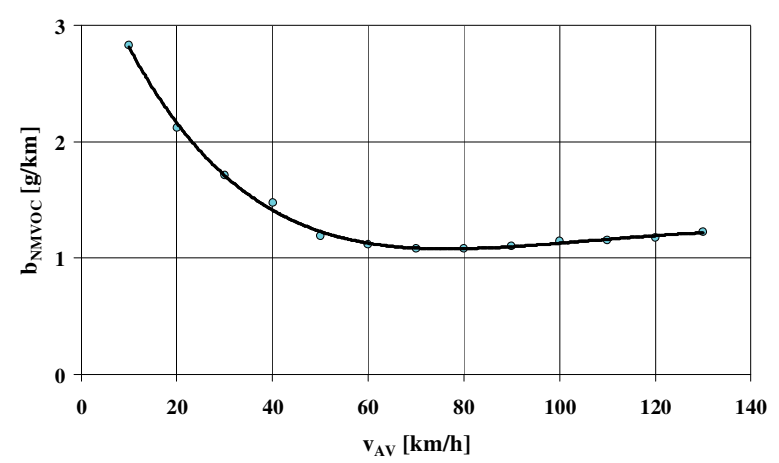

Fig. 26. The characteristic of the specific distance emission of carbon nonmethane volatile organic compounds $-b_{\mathrm{NMVOC}}$ from motorcycles and mopeds

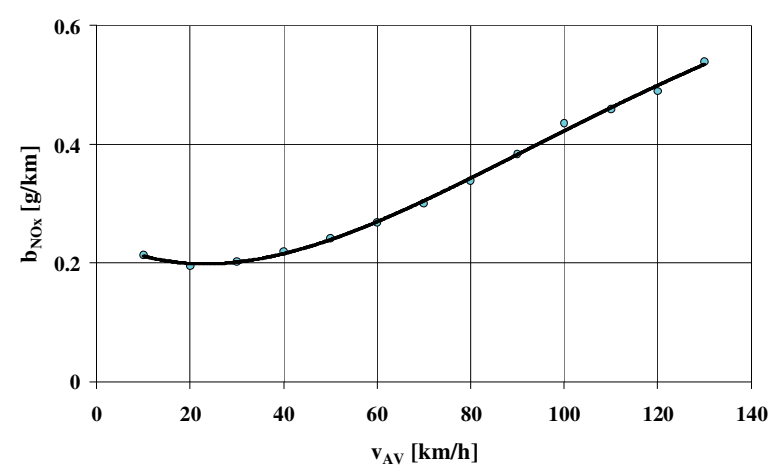

Fig. 27. The characteristic of the specific distance emission of nitrogen oxides $-b_{\mathrm{NOx}}$ from motorcycles and mopeds

The pollutant emission characteristics of motorcycles and mopeds significantly differ from emission characteristics of other cumulated vehicle categories. These are primarily vehicles equipped with spark ignition engines, sometimes two-stroke engines. For these engines, there is a significant impact of the engine load on road emissions of carbon monoxide and, in particular, nitrogen oxides.

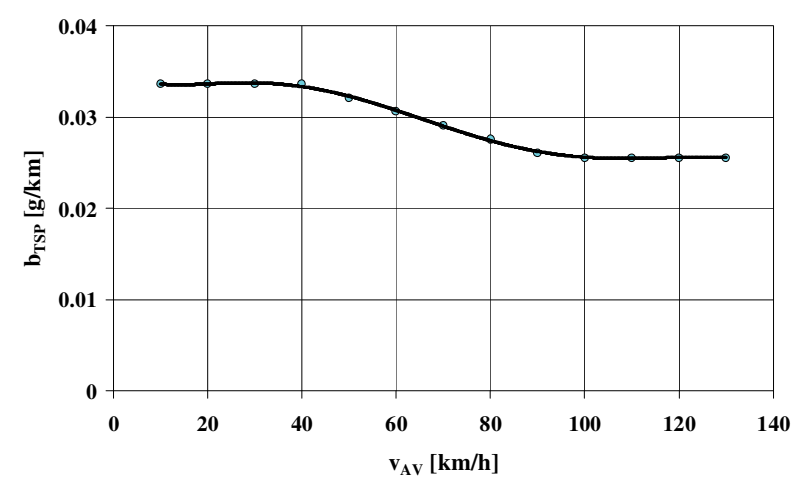

Fig. 28. The characteristic of the specific distance emission of total particulate matter $-b_{\text {TPM }}$ from motorcycles and mopeds

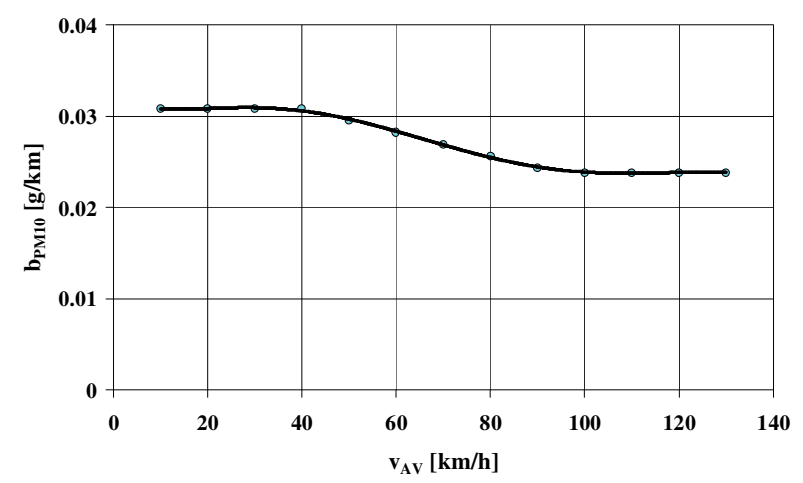

Fig. 29. The characteristic of the specific distance emission of particulate matter PM10 - b $_{\mathrm{PM} 10}$ from motorcycles and mopeds

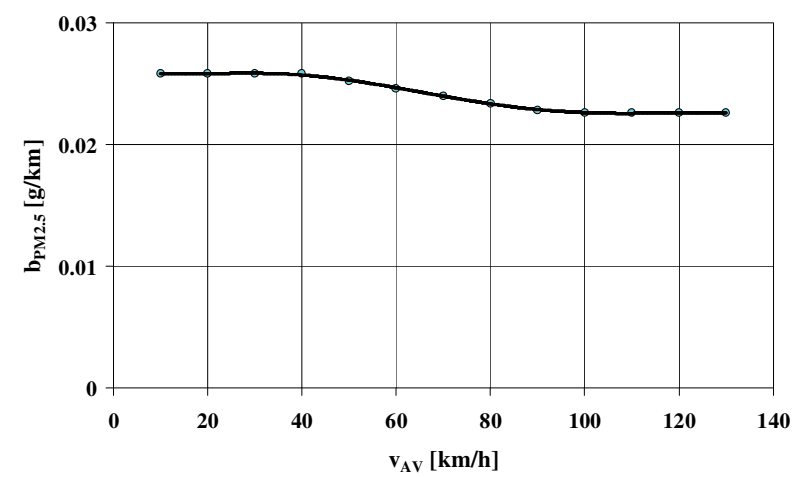

Fig. 30. The characteristic of the specific distance emission of particulate matter PM2.5 - b $\mathrm{b}_{\mathrm{PM} 2.5}$ from motorcycles and mopeds

\section{Recapitulation}

Modeling of pollutants immission is of great practical significance. Measurements of pollution immissions are possible only in selected places, while knowledge about threats in other areas is insufficient. Extensive modeling of emissions and immission of pollution throughout Poland, undertaken by the Institute for Environmental Protection National Research Institute, is a global-scale unique project.

In order to assess the emission of pollutants from motor vehicles, the knowledge of vehicle motion intensity and character, described by the value of vehicle speed, and emission characteristics are of key importance.

This article presents pollutant emission characteristics determined for cumulated categories of motor vehicles for the first time in Poland based on an inventory of pollutant emissions from road transport [12]. 
The determined characteristics represent the correlation consistent with the current state of the knowledge, including characteristics presented in the literature [4], determined based on the INFRAS AG software [11] and numer- ous results of empirical research [6-8]. The results of the current studies on the system developed under the Central Emission Base allow for an optimistic assessment of determined emission characteristics of motor vehicles.

\section{Nomenclature}

$\begin{array}{llll}\mathrm{As} & \text { arsenic } & \mathrm{Ni} & \text { nickel } \\ \mathrm{b} & \text { specific distance emission } & \mathrm{N}_{\mathrm{k}} & \begin{array}{l}\text { number of vehicles in the category „,k” } \\ \mathrm{Cd}\end{array} \\ \mathrm{CO} & \text { cadmium } & \mathrm{NMVOC} & \text { non-methane volatile organic compounds } \\ \mathrm{CO}_{2} & \text { carbon monoxide } & \mathrm{NO}_{\mathrm{x}} & \text { nitrogen oxides } \\ \mathrm{E}_{\mathrm{a}} & \text { annual emission } & \mathrm{Pb} & \text { lead } \\ \mathrm{Hg} & \text { mercury } & \mathrm{PM} 10 & \text { particular matter PM10 } \\ \mathrm{K} & \text { number of elementary categories in the cumu- } & \mathrm{PM}_{2.5} & \text { particular matter PM2.5 } \\ & \text { lative category } & \mathrm{SO}_{2} & \text { sulphur oxides } \\ \mathrm{N} & \text { number of vehicles } & \mathrm{TPM}_{\mathrm{AV}} & \text { total particular matter } \\ \mathrm{NH}_{3} & \text { ammonia } & \mathrm{v}_{\mathrm{AV}} & \text { average velocity }\end{array}$

\section{Bibliography}

[1] BEBKIEWICZ, K., CHŁOPEK, Z., SZCZEPAŃSKI, K., ZIMAKOWSKA-LASKOWSKA, M. Assessment of results of pollutant emission inventory of the road transport sector in Poland in 2000-2015. The Archives of Automotive Engineering - Archiwum Motoryzacji. 2017, 78(4), 5-25.

[2] BEBKIEWICZ, K, CHŁOPEK, Z., SZCZEPAŃSKI, K., ZIMAKOWSKA-LASKOWSKA, M. Issues of modeling the total pollutant emission from vehicles. Proceedings of the Institute of Vehicles. 2017, 1(110), 103-118.

[3] BEBKIEWICZ, K., CHŁOPEK, Z., SZCZEPAŃSKI, K., ZIMAKOWSKA-LASKOWSKA, M. Results of air emission inventory from road transport in Poland in 2014. Proceedings of the Institute of Vehicles. 2017, 1(110), 77-88.

[4] BUWAL (Bundesamt für Umwelt, Wald und Landschaft), INFRAS AG (Infrastruktur-, Umwelt- und Wirtschaftsberatung). Luftschadstoffemissionen des Strassenverkehrs 19502010, BUWAL-Bericht 1995, 255.

[5] CHŁOPEK, Z. The modeling basis of the pollutant emission and the fuel and energy consumption for internal combustion engines of motor vehicles. Combustion Engines. 2015, 162(3), 177-185.

[6] CHŁOPEK, Z., BIEDRZYCKI, J., LASOCKI, J., WÓJCIK. P. Examination of pollutant emissions and fuel consumption at tests simulating the real conditions of operation of a pas-

Katarzyna Bebkiewicz, MEng. - Institute of Environmental Protection - National Research Institute in Warsaw.

e-mail: katarzyna.bebkiewicz@kobize.pl

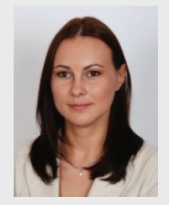

Prof. Zdzisław Chłopek, DSc., DEng. - Professor in the Institute of Environmental Protection - National Research Institute in Warsaw.

e-mail: zdzislaw.chlopek@kobize.pl

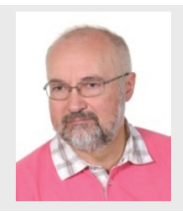

Krystian Szczepański, DSc., DEng. - Director of the Institute of Environmental Protection - National Research Institute in Warsaw.

e-mail: krystian.szczepanski@ios.edu.pl

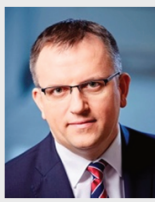

senger car. The Archives of Automotive Engineering. Archiwum Motoryzacji. 2014, 65(3), 3-18, 81-96.

[7] CHŁOPEK, Z., DĘBSKI, B., SZCZEPAŃSKI, K. Theory and practice of inventory pollutant emission from civilization related sources: share of the emission harmful to health from road transport. The Archives of Automotive Engineering - Archiwum Motoryzacji. 2018, 79(1), 5-22.

[8] CHŁOPEK, Z., LASKOWSKI, P. Pollutant emission characteristics determined using the Monte Carlo Method. Eksploatacja i Niezawodność - Maintenance and Reliability. 2009, 2(42), 42-51.

[9] COPERT Training 5. COPERT 5 vs COPERT 4. European Environment Agency. 2016. http://emisia.com/sites/default/ files/COPERT_5_features.pdf. (2019.02.06).

[10] EMEP/EEA air pollutant emission inventory guidebook 2016. European Environment Agency.

[11] INFRAS AG: Handbuch für Emissionsfaktoren des Strassenverkehrs; Version 3.1; Bern 2010.

[12] Poland's Informative Inventory Report 2018. Submission under the UN ECE Convention on Long-range Transboundary Air Pollution and the Directive (EU) 2016/2284 Warszawa. National Centre for Emission Management (KOBiZE) at the Institute of Environmental Protection - National Research Institute. February 2018.

Magdalena Zimakowska-Laskowska, DSc., DEng. Institute of Environmental Protection - National Research Institute in Warsaw.

e-mail: magdalena zimakowska-laskowska@kobize.pl

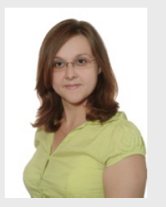

Jakub Lasocki, DEng. - Faculty of Automotive and Construction Machinery Engineering, Warsaw University of Technology.

e-mail: jakub.lasocki@pw.edu.pl 